\title{
The Creative Hub: HR Strategic Function in The Digital Age
}

\author{
Audia Junita ${ }^{1}$ \\ ${ }^{1}$ Business Economic Faculty Universitas Harapan Medan, Indonesia \\ *Corresponding author. Email: audia.junita@yahoo.com
}

\begin{abstract}
The function of managing human resources in organizations has evolved. The adaptability of the human resource management function in the organization is important, so that it is agile in responding to the demands of the times and able to contribute strategically to the performance and competitive advantage of the organization in a sustainable manner. In the digital age, technology-based HR transformation is needed to meet the needs of that era. To carry out technology-based HR transformation, the transformation of competency mastery of HR professionals is needed. Various theoretical studies and existing empirical research have not revealed clearly what kind of role is important to be carried out by the organization's human resources function in the digital age. Therefore, this research was conducted to answer these problems with the literature study method. It is expected that the results of the study can make practical and theoretical contributions to enrich the field of human resource management studies, especially related to the role of the organization's human resource management functions that are appropriate in the digital age.
\end{abstract}

Keywords: HR Function, Creative Hub,Tthe Digital Age.

\section{INTRODUCTION}

The function of human resource management in organizations has evolved from time to time in line with the development of management science [1,2]. The function of human resource management begins with a traditional perspective and technically oriented then develops into a strategic perspective. This change in function demands a different role to meet the needs that arise in each era.

In the digital era, the function of human resources management in organizations is required to carry out different roles to meet the needs that arise in that era. The function of human resources is demanded to be more agile [3, 4] in responding to various demands of environmental changes, able to manage complex data and information for making appropriate human resource decisions and able to contribute to value creation for the organization [3, 4]. The HR function is not only required to play a role as a strategic business partner to execute organizational strategies and bring out the strategic work behavior of organizational members through a series of HR policies/practices [7] but also able to utilize technology in carrying out its functions [5, 8]. Technological transformation requires various forms of adaptation in the work environment, including working methods, working time, relationships with colleagues, coordination systems, evaluation, as well as the function of human resource management.

The development of the digital era is undeniable. It plays an important role in the evolution of the human resource function which demands changes in staffing policies/practices, motivates, and retains employees [9]. Technology is not just a tool, but it is very useful to help improve human resource management with high skills and master knowledge more effectively and efficiently, without eliminating the essence of human being [8]. The capabilities of human resource management in technology-based organizations can significantly improve organizational performance. The emergence of e-HRM concept [10] is not only interpreted in a narrow sense as administrative support for HR functions in internet technology-based organizations that allow human resource management activities to be more efficient but also as a strategic determinant of vital organizational decisions.

The role of HR specialists has become more complex because they have to manage the big data as the basis for strategic decision making in the field of organizational human resources. The strategic competence of HR specialist is very influential in organizational 
performance [10]. HR specialists play an important role in the effectiveness of the implementation of HR functions in organizations $[11,12]$. [13, 14, 15] suggest the set of HR competencies' evolution who can act as strategic business partners, create personal effectiveness, and meet expectations. Internal and external stakeholders as well as achieving business strategic value by managing talent, leadership, and culture that make the organization have the capability to excel in competition, including the ability to use technology and social media to create highperformance organizations.

However, the transformation of the technology-based HR function along with technology competency alone was identified as insufficient to realize the strategic HR function in the organization. The problem related to this is that there has not been explicitly revealed the real concept of the proper strategic HR function in the digital era. Based on this background, this article aims to analyze the new concepts of strategic HR functions needed in the digital era theoretically that can create competitive value for organizations. It is expected that this new role will not only become a discourse but also become an organizational operational tactic that has strategic value

\section{LITERATURE REVIEW}

The function of human resources starts from a classic approach that uses physical, mechanical, and rational approaches in the management of human resources within the organization to increase the efficiency and productivity of organizational work. Then, it develops to a more strategic approach oriented to fulfill the social and psychological needs of workers. Furthermore, in a systematic era, the workers were placed as an important asset that has economic value for the organization. In the competitive era, the value orientation of the human resource management strategic function is becoming increasingly important. HR professionals are required to have diverse competencies that exist at the intersection of the workers and businesses interests and span between individual, organizational, and social contexts. HR professionals are required to be competent in designing structures, processes, and policies that are capable of managing talent well, building organizational capabilities including organizational culture and identity. Thus, organizational members have a deep understanding of organizational values which are manifested in their work behavior. Human resource professionals should be able to leverage the strategic role behavior of talents that are scattered in all lines of the organization. Diagrammatically, several key aspects that characterize each era in the development of the strategic HR function are shown in Figure 1.

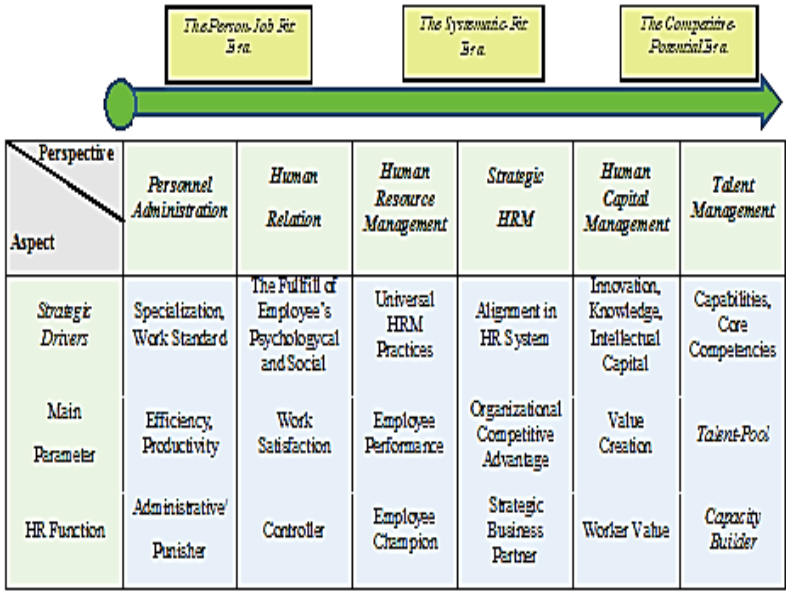

Figure 1 The evolution of HR strategic function

The technical function of human resource management focuses on various activities to improve worker performance (micro-orientation), including activities to increase work efficiency and productivity, division of labor, specialization and standardization of tasks [16]. While the strategic function plays a role in the process of formulating an organizational strategy (strategic business partner), contributes to organizational performance (macro-orientation) [17] (Figure 2), and satisfies the expectations of internal and external stakeholders of the organization [27] which will then provide value to the organization $[18,19]$. The effectiveness of the HR function is measured by how the HR function can deliver value to its stakeholders.

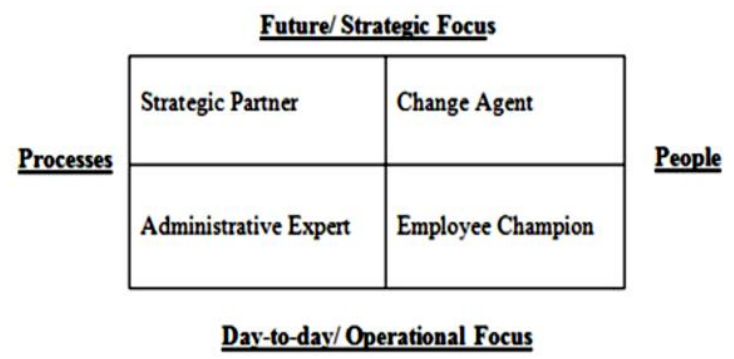

Figure 2 The role of HR function

Source: [17]

Therefore, the human resources department needs to carry out a role transformation in order to be able to identify business realities in the external environment, adapt various human resource strategies in line with reality, improve the professional competence of human resources, and design new roles. Competence means the ability (knowledge, skills, behavior) to carry out specific tasks [20]. HR professionals' competencies exist at the intersection of the interests of workers and business [13] and span between individual, organizational, and social contexts

In a further development, [15] developed the professional competence of human resource as shown in Figure 3. HR professionals have to take control the main 
competencies (core drivers), organizational competence (organization enablers), and tactical competences that support the effectiveness of human resource management (enablers delivery). Human resource professionals must be able to effectively create personal effectiveness, meet the expectations of internal and external stakeholders and achieve business strategic values by managing talent, leadership, and culture that makes the organization have the capability to excel in competition.

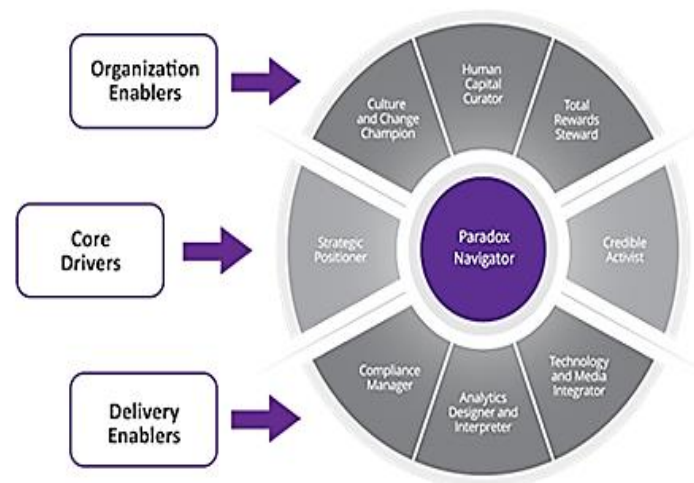

Figure 3 HR professional competencies 2017

Sumber: [15]

\section{METHODS}

The method used to analyze the problem is literature study utilizing various literature and empirical research results that can support the discussion of the problems raised.

\section{RESEARCH RESULT AND DISCUSSION}

Digitalization is a market reality, and we must follow it. Digitalization has changed various aspects of business activities including business processes, management, collaborative information exchange, marketing, the interaction between business actors in the ecosystem, and the need for human resources to support business as a result of the use of digital technology [21]. Digital business is not only oriented towards creating value for customers but also makes the business move more agile [22], creating competitive business processes by offering differentiation to be competitive. Technology is one of the differentiators [23].

However, technology is not the sole determinant of digital business success. How to use digital elements and technology in business is a decision made by the human mind. Humans are the drivers and controllers of change. Humans are managers of knowledge so that it has economic value for the business. Humans are assets (investments), instead of just resources, that will generate value and competitive advantage for businesses in the digital era and the knowledge economy [24].

Internal business processes involve humans as the driving force. This is in line with what was stated by [25] that technology acts more as an enabler and not a substitute for humans. Technology is possible to reduce the use of human labor in business, but its presence in digital business is no less important than the technology itself. The importance of humans and their management strategies in the digital economy is to anticipate the fluctuation of dynamic business changes [26] and support the business process [27]. Various studies have shown that humans play an important role in the use of information technology to contribute maximally to the achievement of business performance [28, 29].

Organizational value can also be increased through the adoption of information technology that facilitates business processes including human resource management functions which can reduce costs and improve services [8]. Technology is a mechanism or process through which an organization's products or services are produced [30]. The importance of technology adoption in the human resource management function is undeniable. Technology is not just a tool, but it is very useful to help improve human resource management with high skills and master knowledge more effectively and efficiently without eliminating the essence of human existence in organizations [8]. The key element of technology adoption in HR management is to create value from strategic decision making related to human resources that affect the business value chain so that it can run in an integrated manner between corporate strategy, team and individual goals.

Digitalization is found in organizations in the form of smart operations by using platforms that are accessible to many parties. Big data is a general concept used in structured human resource management and is used to provide value to organizations [8]. Digital solutions enable organizations to analyze a large amount of data that needs comprehensively in business processes according to the time needed [31].

Specifically, the various human resource management practices that are the responsibility of the organization's human resources function are made easier through the use of technology tools according to organizational needs, including portals, database-based human resource information systems (HRIS) computerized, Enterprise Resource Planning (ERP) [32], a cloud HR system that transforms HR functions into a "smart platform" [33].

HRIS was identified as relevant to assist the HR function in the organization both in carrying out administrative and analytical functions in the management of human resources in the organization [5]. [34] also explained that the advantages of utilizing HRIS in an organization are not limited to the HR department, but also for employees who enable them to self-service their respective personnel data, including accessing, updating, validating data into the system. People analysis is used to manage a wide variety of business challenges 
from planning, hiring, performance measurement, compensation to workforce retention. These various technology-based human resource management platforms are often connected with various service provider agencies that help provide professional HR management services within the organization to provide labor with the quantity and quality needed effectively and efficiently, for example in recruitment and selection to meet company needs of workforce, training, performance appraisal, salary distribution, and so on.

In general, the adoption of technology changes the management order in organizations. The advancement of information technology has changed rapidly work context, process, and structure, thus requiring a redefinition of functions, tasks, roles, and responsibilities in organizations including ways to manage human resources appropriately [35]. Digital-based organizations are characterized by a team-based work structure that relies on knowledge, flexible work designs, fragmented business processes, involving work collaboration with various partners and requires mastery of technological competencies that support work effectiveness. The keywords inherent in digital-based organizational strategies are the use of digital platforms and collaboration between business partners to ensure the business value chain runs well and market needs are served effectively and in a time and cost-efficient manner and between parties are increasingly connected [27].

As a business that interacts with various work partners both internally (between functions) and externally (across individuals and organizations), the digital business can be analogous to a virtual company that collaborates with several independent business companies to provide products and services within a limited time to specific clients. The right work structure for a digital business is described as a network or collaborative work structure [30]. The main consideration in using this network structure is that the company has few core competencies, so it needs to involve external partners specifically to anticipate rapid technological developments and complex business processes.

For this reason, the HR function in digital-based business organizations is required to make changes. The use of digital technology in organizational business processes will reduce the use of human labor. Digitalbased organizations tend to meet workforce needs by utilizing e-recruitment and e-selection [36]. Even to get a highly competent and ready-to-use workforce, organizations rely on external sources in collaboration with professional service providers. [37] termed the activity with numerical flexibility. This is consistent with the free-agent human resource strategy model [38, 39] or relatively the same as the alliance/partnership employment model [40]. This strategy allows the organization to find talents who can provide value to the organization. Organizational members will also have diverse backgrounds, so they need better collaboration skills. Diversity can be accommodated by using technology.

Interaction and communication between parties inside and outside the organization are increasingly open with digitalization. Digital-based organizations facilitate and allow employees to communicate work through a variety of communication platforms including intranets and extranets, electronic mail, social networking, videoconferencing, teleconferencing, and emeetings/collaboration [20, 41]. Various technologybased communication media options allow the HR department not only to be involved in managing internal human resources but also involving vendors, customers, service providers, or other strategic partners who work with the organization.

The opening of communication media in organizations by utilizing digital technology supports organizations to implement teamwork. The various internal and external parties involved in the organization's business process are partnership teams connected to the technology media (virtual teams). They have to complete various work processes and produce products/services to the community in unlimited space and time. The function of HR to coordinate these various parties creatively combine with the interactive use of technology according to the organization's work needs.

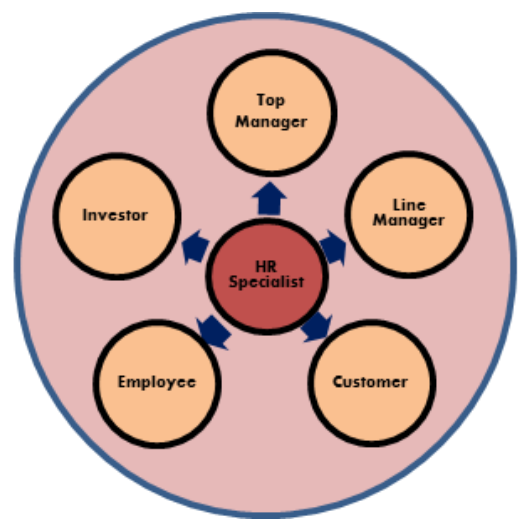

Figure 4 Creative hub role of HR

In such conditions, the HR function act as a strategic link between the various organizational strategic partners. Humans remain become the prime mover of the organization. Like the network teams or network structure [30], the HR function is positioned in the middle as an axis connected to various internal and external parties. Work relations (interactions) with partners can take place well through the use of interactive digital extranet technology and other technologies to ensure that information flows easily and openly between the parties concerned.

In line with the form of work structures and HR functions in digital-based organizations, HR specialists in digital business also play a new role as a creative hub 
(Figure 4) that connects various parties (stakeholders) to support business processes running well. Human resource specialists in digital business interact with virtual team members who operate across space, time, and organizational boundaries that are spread out and connected through information technology to achieve business goals. Mastery of technology from HR specialists must also be very good to support the strategic HR function in the digital business to run well.

The new role of the HR specialist as a creative hub requires a variety of competencies to carry out administrative as well as strategic functions in the organization. In the digital era, human resource professionals are required to be competent to make changes and manage a conducive work culture (change champion) for technology-based work, able to build relationships (dialogue) based on trust (relationship of trust) with internal and external stakeholders, able to use technology and social media (technology and media integrator), as well as being actively involved in organizational strategic decision making (strategic positioner) to create value and high-performance organizations.

The involvement of HR specialists in organizational strategic decision making requires interaction and involvement with various parties who control a variety of information. For this reason, HR specialists need creative strategies, knowledge, and experience as well as innovative ideas to process information into strategic decision solutions. Creative ideas are generated through open communication systems, teamwork with various parties, interactive problem solving, work flexibility that gives work autonomy, all of which are easier to implement by utilizing technology.

\section{CONCLUSION}

The function of managing human resources in an organization has evolved from time to time. It needs various adjustments be made to the times. The digital era demands various forms of adaptation in the work environment, including working methods, working time, relationships with colleagues, coordination systems, evaluation, as well as the function of managing human resources. Digital-based organizations are characterized by a team-based work structure that relies on knowledge, flexible work designs, fragmented business processes, involving work collaboration with various partners and requires mastery of technological competencies that support work effectiveness. In line with the form of work structures and HR functions in digital-based organizations, HR functions and specialists play a new role as a creative hub that connects various parties (stakeholders) to support business processes running well and create value for the organization.
HR specialists need creative strategies, knowledge, and experience as well as innovative ideas to transform information into strategic decision solutions. Creative ideas are generated through open communication systems, teamwork with various parties, interactive problem solving, work flexibility that gives work autonomy, all of which are easier to implement by utilizing technology.

\section{REFERENCES}

[1] J. M. Shafritz and J. S. Ott. Classics of Organization Theory, 5th ed. Harcourt College Publishers, 2001.

[2] M. S. M. Khan and U. Mushtaq, Evolution of Strategic Role of Organization's Human Resource Management: an Overview, Journal of Bussiness \& Economics 7(1) 2015 236-257.

[3] E. Rubio, Building a Truly 'Agile' Human Resources Function: How to Do It?," HR Strategy and Planning Exc Ess. 2018.

[4] N. Bushey. Enhancing Organizational Agility within Tthe Human Resources Function, A research project, The Pepperdine Graziadio Business School, California, USA, 2019.

[5] A. Qadir and S. Agrawal, HR Transformation through Human Resource Information System: Review of Literature, Journal of Strategy HRM 6(1) 2017 30-38.

[6] P. Dahlbom, N. Siikanen, P. Sajasalo, and M. Jarvenpää, Big Data and HR Analytics in The Digital Era, Baltic Journal of Management 15(1) 2018 120-138. DOI: 10.1108/BJM-11-2018-0393.

[7] B. Becker, M. Huselid, and D. Ulrich. The HR Scorecard: Linking People, Strategy, and Performance, Harvard Business School Press, 2001.

[8] C. Tataru, Human Resources in The Digital Age: A Manager's Realities and Perspectives, Review of Int Comparative Manag,ement 20(4) 2019 473-480.

[9] D. L. Stone, D.L. Deadrick, K.M. Lukaszewski, and R. Johnson, The Influence of Technology on The Future of Human Resource Management, HRM Review 25(5) 2015 216-231.

[10] M. Voermans and M. Van Veldhoven, Attitude towards E-HRM: an Empirical sStudy at Philips, Personnel Review 36(6) 2007 887-902.

[11] R. R. Smith, Human Capital in The Human Resource Function: The Positioning and Impact of The Chief Human Resource Officer (CHRO), Dissertation, Singapore Management University, Singapore, 2015. 
[12] W. Brockbank, D. Ulrich, and C. James, Trends in Human Resource Competencies, University of Michigan School of Business, 1997.

[13] D. Ulrich, W. Brockbank, D. Johnson, K. Sandholtz, and J. Younger, HR Competencies: Mastery at The Intersection of People and Business, Society for Human Resource Management, 2008.

[14] D. Ulrich, J. Allen, W. Brockbank, J. Younger, and M. Nyman, HR Transformation: Building Human Resources from The Outside Inc., McGraw Hill, 2009b.

[15] D. Ulrich, D. Kryscynski, M. Ulrich, and W. Brockbank, Victory through Organization: Why The War for Talent is Failing Your Company and What You Can Do About It, McGraw-Hill Education, 2017.

[16] P. Boselie, C.Brewster, and J. Paauwe, In Search of Balance - Managing The Dualities of HRM : an Overview of The Iissues," Personnel Review, 3(5) 2009 461-471.

[17] D. Ulrich, Human Resource Champions: The Next Agenda for Adding Value and Delivering Results, Harvard Business School Press, 1997.

[18] L. Dyer, Bringing Human Resources into the Strategy Formulation Process, Human Resource Management (pre-1986) 22( 3) 1983 257-271.

[19] P. M. Wright and G. C. McMahan, Theoretical Perspectives for sStrategic Human Resource Management, Journal of Management 18(2) 1992 295-320.

[20] R. L. Mathis and J. H. Jackson, Human Resource Management, 13th ed. South-Western Cengage Learning, 2011.

[21] A. Aagard, Digital Business Models Driving Transformation and Innovation. Palgrave MacMillan, 2019.

[22] N. Perkin and P. Abraham, Building The Agile Business through Digital Transformation. Kogan Page Limited, 2017.

[23] J. Berman, Digital Transformation: Opportunities to Create New Business Models, Strategy \& Leadership 40(2) 2012 16-24.

[24] A. Mayo, Human Resources or Human Capital ? Managing People as Assets. Gower Publishing Limited, 2012.

[25] A. Khanna, How do You Digitize HR without Losing The 'Human' in Human Resources?, Gurgaon, 2016 3-4.
[26] C. J. Chen and J. W. Huang, Strategic Human Resource Practices and Innovation Performance: The Mediating Role of Knowledge Management Capacity, Journal of Bussiness Res. 2(1) 2009104 114.

[27] D. Chaffey, Digital Business and E-commerce Management: Strategy, Implementation and Practice, 6th ed., Pearson Education Limited, 2015.

[28] J. Crawford, L. N. K. Leonard, and K. Jones, The Human Resource's Influence in Shaping IT Competence, Industrial Mangement \& Data System 111(2) 2011 164-83.

[29] H. Chae, C. Koh, and V. Prybutok, Information Technology Capability and Firm Performance: Contradictory Findings and Their Possible Causes, MIS Quarterly 38(1) 2014 305-326.

[30] S. L. McShane and M. A. Von Glinow. Organizational bBehavior: Emerging rRealities for The Workplace Revolution, 4th ed. The McGrawHill Companies, Inc., 2008.

[31] J. Bersin, T. McDowell, A. Rahnema, and Y. Van Durme, The Organization of The Future: Arriving Now, in Global Human Capital Trends 2017: Rewriting The Rules for The Digital Age, Deloitte University Press, 2017, pp. 19-28.

[32] S. Greengard, Putting HR Software to Work, Workforce 91999 4-10.

[33] L. Collins, D. Fineman, and A. Tsuchida, People Analytics: Recalculating The Route, In Global Human Capital Trends 2017: Rewriting The Rules for The Digital Age, Deloitte University Press, 2017, pp. 97-106.

[34] R. D. Hoff, The Impact of Cafeteria Benefits on The HRIS, Personnel Journal 62(4) 1983 282-283.

[35] A. Manuti and P. D. De Palma. Digital HR: a Critical Management Approach to The Digitilization of Organizations. Palgrave MacMillan, 2018.

[36] R. T. Cober, D. J. Brown, P. E. Levy, L. M. Keeping, and A. L. Cober, Organizational Websites: Website Content and Style as Determinants of Organizational Attraction, International Journal of Select and Assess 112003 158-169.

[37] Derek Torrington, Laura Hall, S. Taylor, and C. Atkinson, Human Resource Management. Pearson Education Limited, 2014.

[38] J. Bratton and J. Gold. Human Resource Management: Theory \& Practice, 5th ed. Palgrave MacMillan, 2012. 
[39] P. Bamberger, M. Biron, and I. Meshoulam, Human Resource Strategy: Formulation, Implementation and Impact, 2nd. ed. Taylor \& Francis, 2014.

[40] D. P. Lepak and S. A. Snell, Examining The Human Resource Architecture: The Relationship among Human Capital, Employment, and Human Resource Configurations, Journal of Management 282002 517-543.

[41] J. M. Ivancevich, R. Konopaske, and M. T. Matteson. Organizational Behavior and Management, 10th ed. The McGraw-Hill Companies, Inc., 2014. 